\title{
Lymphatic Clinical Severity Score (LCSS): Proposal of a New Clinical Method for the Appraisal of the Peripheral Lymphatic Diseases
}

\author{
Sandro Michelini ${ }^{1}$, Marco Cardone ${ }^{1}$, Alessandro Fiorentino ${ }^{1}$, Alessandro Failla ${ }^{1}$, Giovanni Moneta ${ }^{1}$, Serena \\ Michelini ${ }^{2}$ and Guido Valle*3 \\ ${ }^{1}$ Hospital San Giovanni Battista-ACISMOM, Rome, Italy \\ ${ }^{2}$ Specialty School in "Medicina Fisica e Riabilitativa" Hospital Sant'Andrea, University of Rome "La Sapienza", Italy \\ ${ }^{3}$ Nuclear Medicine Unit, IRCCS “Casa Sollievo della Sofferenza”, San Giovanni Rotondo, Italy
}

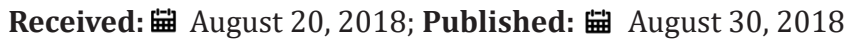

*Corresponding author: Guido Valle MD, Hospital San Giovanni Battista-ACISMOM, Rome, Italy

\begin{abstract}
An accurate clinical appraisal of lymphoedema patients is often a challenge because the lymphoedema disability scales commonly used in rehabilitation are not completely suitable to a proper classification of such subjects. Therefore, the choice of how charging the single lymphomatous patient to health public and private insurance systems worldwide is difficult. In order to address this issue, the authors defined and propose an evaluation system, called Lymphatic Clinical Severity Score (LCSS) that, analogously to the Venous Clinical Severity Score used in the assessment of venous chronic diseases, is aimed to assign the patient to a determinate clinical level. The LCSS score therefore results a useful parameter in evaluating whether to take in charge a patient is appropriate and how to do it. The LCSS has been successfully tested on 185 subjects with primary and secondary lymphoedema. The LCSS score determination can be repeated at the end of treatments and can be recalculated in the follow-up allowing a numerical temporal evaluation of the sickness.
\end{abstract}

Keywords: Lymphoedema; clinical assessment; Lymphatic Clinical Severity Score

\section{Introduction}

The need to synthetically classify the clinical seriousness level of patients with venous chronic disease suggested the development of a score system, the Venous Clinical Severity Score (VCSS) that corresponds to the sum of many different scores relative to the degree of the severity of the clinical findings that characterize each patient [1,2]. For some items, in the follow-up, it is possible to observe a decrease in the total score that reflects a clinical improvement and indicates a reduced, if still present, need for assistance. Lymphoedema patients present analogous classification problems and often public and private insurance systems dispute about the assignment of a patient to the regimen of assistance chosen (outpatients' department, Day Hospital, admission as an inpatient) [3-6]. Both primary and secondary lymphoedema are chronic disorders in which the interstitium is soaked by fluids with elevated protein concentration [4-8]. The high protein concentration in the interstitial fluid triggers the fibroblasts' transformation into fibrocytes with enhanced production of collagen resulting in tissue sclerosis.

This is the reason because lymphoedema induces an early fibrosis that compromises the full recovery of the oedema itself. These mechanisms facilitate both acute and chronic phlogosis
[9] as well as dystrophic and dysplastic processes and, in some cases, trigger the genesis of sarcomas [10]. The evaluation scales commonly used in rehabilitation (Barthel, FIM, SMWT etc.) [1114] are often unreliable to describe and emphasize all the psychosomatic aspects observed in lymphoedema patients and this pave the way to claims and contestations with reference to the charge of these subjects by public and private insurance systems. In order to address this issue and to provide an objective tool, the authors developed a score system, the Lymphatic Clinical Severity Score (LCSS), aimed to evaluate the peripheral lymphatic both primary and secondary disorders. LCSS, analogously to the Venous Clinical Severity Score (VCSS) already used in the assessment of venous chronic diseases, is aimed to assign the patient to a determinate clinical level. The LCSS has been successfully clinically tested.

\section{Materials and Methods}

\section{Methods}

Lymphoedema is often associated to a series of anatomicfunctional complications that result, sooner or later, in the corresponding clinical findings with different intensity levels. Among them, the most important are: 

a) Oedema
b) Increase in tissue texture (consistency)
c) Inflammation $[15$
d) Cutaneous dystrophy [16]
e) Recurrent dermato-lymphangio-adenitis (often erisipela- like)
f) Pain [17]
g) Lymph ulcerations [18]
h) Joint involvement with functional impairment [16,17]
i) Muscular hypotrophy $[4,10,17]$

j) From all these findings the need to wear an elastic garment, at least in some hours of the day $[1,2,4,16]$, could spring out. This need must be considered as a tenth element in the evaluation of patient suffering from lymphoedema.

Analogously to VCSS rating criteria, in LCSS we assigned four possible severity levels to each of the ten previously described conditions. For each item the assigned score can ranges from 0 to 3 (Table 1). Particularly, the following score assignation criteria have been adopted (Table 2)

Table 1: Clinical Score According to Less.

\begin{tabular}{|c|c|}
\hline LCSS & Severity of Each Item \\
\hline 0 & Absent/Not significant \\
\hline 1 & Mild \\
\hline 2 & Moderate \\
\hline 3 & Severe \\
\hline
\end{tabular}

Table 2: Severity Score (Clinical History and Physical Examination) Assignment Grid.

\begin{tabular}{|c|c|c|c|c|}
\hline Attribute & None $=0$ & Mild = 1 & Moderate = 2 & Severe $=3$ \\
\hline Lymphatic oedema & None & $\begin{array}{l}\text { Occasional swelling with } \\
\text { spontaneous regression }\end{array}$ & Permanent oedema & $\begin{array}{c}\text { Elephantiasis with loss of normal } \\
\text { morphology of the limb }\end{array}$ \\
\hline Tissutal consistency increase & None & Focal & $\begin{array}{l}\text { Iinvolvement limited to } \\
\text { distal third of limb }\end{array}$ & $\begin{array}{l}\text { Involvement of the knee and proximal } \\
\text { parts of the limb. }\end{array}$ \\
\hline Inflammation & None & $\begin{array}{l}\text { Limited phlogosis involving less } \\
\text { than third of limb }\end{array}$ & $\begin{array}{l}\text { Diffuse phlogosis involving } \\
\text { less than a third of a limb. }\end{array}$ & $\begin{array}{l}\text { Diffuse phlogosis involving more than } \\
\text { a third of a limb. }\end{array}$ \\
\hline Skin dystrophy & None & Limited to the marginal area & $\begin{array}{l}\text { Diffuse involvement limited } \\
\text { to less than a third of limb }\end{array}$ & $\begin{array}{l}\text { Diffuse involvement interesting more } \\
\text { than a third of a limb. }\end{array}$ \\
\hline $\begin{array}{l}\text { Recurrent Dermato- } \\
\text { lymphangio-adenitis }\end{array}$ & None & History of only one episode & 2 history of two episodes.. & History of more than 2 episodes \\
\hline Pain & Absent & $\begin{array}{l}\text { Occasional. No restricton to daily } \\
\text { activities nor need for drugs. }\end{array}$ & $\begin{array}{c}\text { Moderate restriction of } \\
\text { daily activities. Occasionally } \\
\text { use of drugs }\end{array}$ & $\begin{array}{l}\text { Severe limitation of daily activities or } \\
\text { need for a regular use of drugs }\end{array}$ \\
\hline Lymph ulcerations & None & 1 Lymph ulceration & 2 Lymph ulcerations & More than 2 active lymph ulcerations \\
\hline $\begin{array}{l}\text { Articular involvement (most } \\
\text { important Joint of the limb) }\end{array}$ & None & Involving 1 great joint of the limb & $\begin{array}{l}\text { Involving } 2 \text { great joints of } \\
\text { limb }\end{array}$ & $\begin{array}{l}\text { Involving the three great joints of } \\
\text { limb }\end{array}$ \\
\hline Muscular Hypotrophy & None & Limited to marginal area & $\begin{array}{l}\text { Diffuse, involving less than a } \\
\text { third of the limb }\end{array}$ & $\begin{array}{l}\text { Diffuse, involving more than a third } \\
\text { of limb }\end{array}$ \\
\hline Compression therapy & None & Intermittent use of garment & Wears garment all the day & Full compliance to the garment \\
\hline
\end{tabular}

a) Oedema. $0=$ none. $1=$ occasional swelling with spontaneous regression. 2 = Permanent oedema. 3 = Elephantiasis with loss of normal morphology of the limb.

b) Tissutal consistency increase. $0=$ none. $1=$ focal. $2=$ involvement limited to distal third of limb. 3 = involvement of the knee and proximal parts of the limb.

c) Inflammation. $0=$ none. $1=$ Limited phlogosis involving less than third of limb. 2 = Diffuse phlogosis involving less than a third of a limb. 3 = Diffuse phlogosis involving more than one third of a limb.

d) Skin dystrophy. $0=$ none. $1=$ Limited to the marginal area. 2 = Diffuse involvement limited to less than a third of limb. $3=$ Diffuse involvement interesting more than one third of a limb.

e) Recurrent dermato-lymphangio-adenitis. $0=$ none. $1=$ history of only one episode. $2=2$ history of two episodes. $3=$ history of more than 2 episodes. f) Pain. 0 = Absent. 1 = Occasional. No restriction to daily activities nor needs for drugs. 2 = Moderate restriction of daily activities. Occasionally use of drugs. $3=$ Severe limitation of daily activities or need for a regular use of drugs.

g) Lymph ulcerations. $0=$ none. $1=1$ ulcer. $2=2$ ulcers. $3=$ more than 2 active lymph ulcerations.

h) Articular involvement. $0=$ none. $1=$ Involving 1 great joint of the limb. 2 = Involving 2 great joints of limb. $3=$ Involving the three great joints of limb.

i) Muscular hypotrophy. $0=$ none. $1=$ Limited to marginal area. $2=$ Diffuse, involving less than a third of the limb. $3=$ Diffuse, involving more than one third of limb.

j) Compression therapy. $0=$ none. $1=$ Intermittent use of garment. 2 = Wears garment all the day. $3=$ Full compliance to the garment. 


\section{Patients}

In order to assess the reliability of this score and assignation system 185 patients with lymphoedema of the limbs and/or of the external genitalia (81 $\mathrm{M}$ and 104 females, age range 0-77 y 72 with primary and 113 with secondary lymphoedema,) have been classified according to LCSS criteria after the collection of an accurate clinical history and a careful physical examination. In each case the findings were properly recorded in the Excell grid. The recommended therapeutic modality regimen springs, for every patient, from his/her LCSS total score and from the consequent attribution to a clinical level (Table 3). An exemple of LCSS attribution is illustrated in (Table 4) that shows how, in each patient, the LCSS corresponds to the sum of the ten scores.

Table 3: Loss and Consequent Therapeutic Indications.

\begin{tabular}{|c|c|c|}
\hline Clinical Level & Total Score & Therapeutic Indications \\
\hline Not significant & $0-5$ (Figure 1 ) & No Treatment \\
\hline Mild & 6-15 (Figure 2) & Consulting room \\
\hline Moderate & 16-22 (Figure 3) & Day Hospital \\
\hline Severe & 23-30 (Figure 4) & Admission as an inpatient \\
\hline
\end{tabular}

Table 4: Exemple of Card Fullfilling With Patient's Data, With Lcsss And Determination of Total Score.

\begin{tabular}{|c|c|c|c|c|c|}
\hline Patient Name Examination Date & \multicolumn{5}{|c|}{ DOB } \\
\hline \multirow{2}{*}{ Attribute } & \multicolumn{5}{|c|}{ Scores } \\
\hline & 0 & 1 & 2 & 3 & \\
\hline Lymphatic oedema & & & 2 & \\
\hline Tissutal consistency increase & & 1 & & & \\
\hline Inflammation & & 1 & & & \\
\hline Recurrent Dermato-lymphangio-adenitis & & & 2 & \\
\hline Pain & & 1 & & \\
\hline Lymph ulcerations & 0 & & & \\
\hline $\begin{array}{c}\text { Articular involvement (with special reference } \\
\text { to the joint of the limbs) }\end{array}$ & & & 2 & & \\
\hline Muscular hypotrophy & & 1 & & & \\
\hline Compression therapy & & & 2 & & \\
\hline TOTAL & 0 & 5 & 8 & 0 & 13 \\
\hline
\end{tabular}

Notice: This subject's LCSS resulted $=13$, with indication to a treatment as an outpatient

According to the final sum of score four clinical levels can be identified:

a) Total score ranging from 0 to 5 : no charge by the health insurance systems is justified; $\mathrm{n}=19 \mathrm{pts}$

b) Total score ranging from 6 to 15: these subjects are properly treated as outpatients; $\mathrm{n}=47 \mathrm{pts}$.

c) Total score ranging from 16 to 22: these patients may be admitted to Day Hospital regimen; $\mathrm{n}=59$.

d) Total score ranging from 23 to 30: these subjects can properly be treated as inpatients $n=74$.

The patients assigned to the levels from 1 to 3 underwent a personalized decongestive integrated physical treatment of different intensity and duration. In all cases a definitive elastic garment was prescribed. The final score was, in each subject, recalculated after the end of the treatment. The difference between the initial and the final total score resulted to be a suitable, numerical quantification of the improvement induced by the treatment. A comparison was also been performed, at enrolling, between LCSS level assignations and the clinical staging determination according to the ISL Consensus Document $[10,11]$ that was also performed on all the 185 patients enrolled in our study (Tables 5 \& 6).

Table 5: Staging According to The International Society of Lymphology (ISL).

\begin{tabular}{|c|c|}
\hline ISL Clinical Stages & Corresponding Clinical Features \\
\hline 0 & $\begin{array}{c}\text { No oedema but significant risk of its clinical } \\
\text { appearance }\end{array}$ \\
\hline I & $\begin{array}{c}\text { Oedema totally regressing by treatment (pitting } \\
\text { oedema) }\end{array}$ \\
\hline II & $\begin{array}{c}\text { Oedema with tissue fibrosis, only partially } \\
\text { regressing by treatment (no pitting oedema ) }\end{array}$ \\
\hline III & $\begin{array}{c}\text { Elephantiasis with skin lesions and relapsing } \\
\text { infections }\end{array}$ \\
\hline
\end{tabular}

Table 6: Comparison Among ISL-Determined Clinical Stages and The Assigned Loss.

\begin{tabular}{|l|c|c|c|c|}
\hline & Stage 0 & Stage 1 & Stage 2 & Stage 3 \\
\hline LCSS Level 0 & 10 & 5 & 4 & 0 \\
\hline LCSS Level 1 & 9 & 21 & 23 & 32 \\
\hline
\end{tabular}

Notice: That differences among LCSS levels and ISL stages were highly statistically significant in all cases $(p<0.001$ at chi square test).

\section{Results}

a) According to the reported criteria the studied population of 185 patients has been classified in the following clinical levels:

b) Clinical level 0 (total score ranging between 0 and 5): 19 patients $(10.3 \%)$. These subjects were not assigned to any kind of treatment (Figure 1).

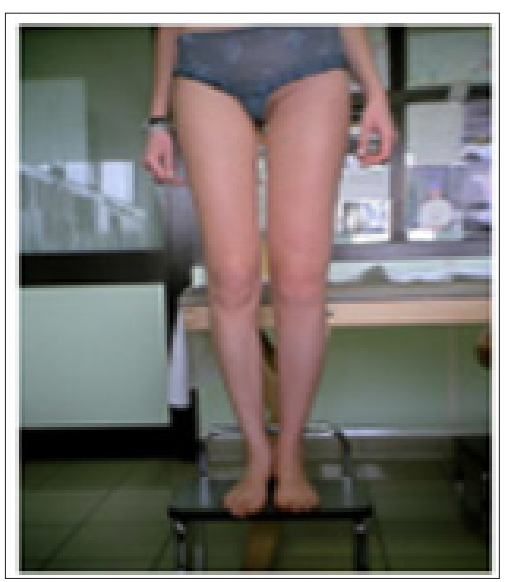

Figure 1: Exemple of a not significant lymphoedema of the left lower limb. 
c) Clinical level 1 (total score ranging between 6 and 15): 85 patients (46\%). These subjects were treated as outpatients (Table 3) and (Figure 2).

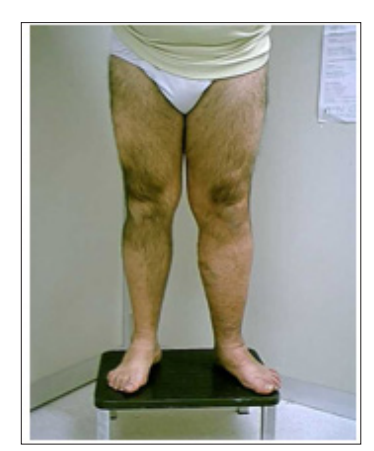

Figure 2: Exemple of patient with moderate lymphoedema of left lower limb.

d) Clinical level 2 (total score ranging between 16 and 22). 47 patients (25.4\%). This group has been treated in Day Hospital (Table 3) and (Figure 3).

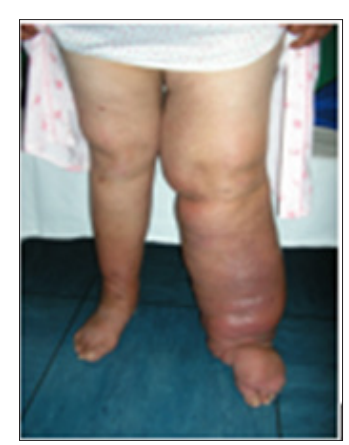

Figure 3: Exemple of patient with severe lymphoedema of the left lower limb.

e) Clinical level 3 (total score ranging between 23 and 30): 34 patients (18.3). These subjects have been admitted as inpatients in order to receive an integrated, intensive, decongestive physical treatment (Table 3) and (Figure 4).

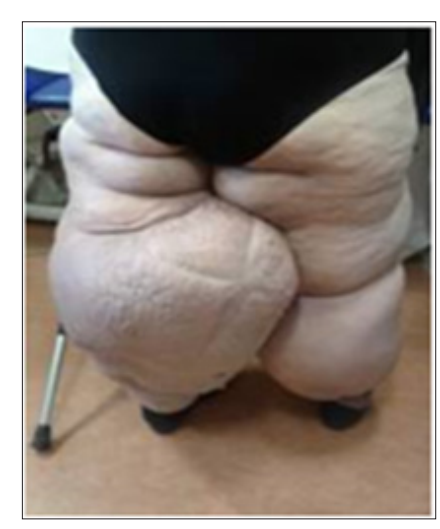

Figure 4: Exemple of a patient with highly disabilitating lymphoedema.

At the end of the treatment the following total scores and changes were recorded: a. Patients assigned to level 0 obviously did not showed, any change.

b. Patients assigned to level 1 showed in the post-treatment total score a mean decrease of $37 \%$ compared to the baseline.

c. Patients assigned to level 2 showed a final total score mean reduction of $42.5 \%$ compared to baseline.

d. Patients assigned to level 3 showed a final total score mean reduction of $38.4 \%$ compared to baseline.

Regarding the comparison between the LCSS level assignation and the ISL clinical staging no full concordance has been observed $(\mathrm{p}<0.001)$. In particular we have founded:

a. The ISL stage 0 corresponds to $0-2$ levels of LCSS.

b. The ISL stage I corresponds to 0-2 levels of LCSS.

c. The ISL stage II corresponds to 0-3 levels of LCSS.

d. The ISL stage III corresponds to 1-3 levels of LCSS and, vice versa:

e. The 0 level of LCSS corresponds to 0-II ISL stages.

f. The 1 level of LCSS corresponds to 0-III ISL stages.

g. The 2 level of LCSS corresponds to 0-III ISL stages.

h. The 3 level of LCSS corresponds to II-III ISL stages.

\section{Discussion and Conclusion}

LCSS represents a simple and reliable method of assignment of a patient to a determinate severity level and consequently to a defined assistance modality. Regarding the comparison between the LCSS level assignation and the ISL clinical staging it must be considered that LCSS does not intend to replace the ISL classification because this latter gives descriptive classes whilst LCSS refers to severity-parameters and disability degree (score) assessment. Therefore, LCSS will hopefully result a useful criterion to guide the patients' assignment choices of both private and public insurance health systems. Moreover, the comparison of the baseline and of the post-therapy LCSS scores will provide a useful way to assess the effectiveness of the adopted treatments. It is noteworthy that in the clinical history of the disease the LCSS may improve or impair. The modality of treatment must be chosen consequently to the updated clinical level. Obviously, there are irreversible scores, like the number of the previously suffered lymphangites, that will not decrease in the follow-up, even though therapeutic treatment.

Otherwise, it is important to underline that the score assigned to this finding reflects an irreversible anatomic-functional damage and, consequently weighs as partial component of the total score in an unaffected way in all subsequent clinical controls. The proposed method for the clinical assessment of peripheral lymphatic disease is inexpensive, reliable, safe and easy to perform. Analogously to VCSS, that successfully entered in the clinical practice long time ago, the LCSS is the expression of the severity of the sickness and of the clinical burden. Moreover, it is a simple key to the standardization 
of the treatments and is a very useful tool in the assessment of the economic managing of lymphatic peripheral disease. It also represents a way to avoid claims about the therapeutic regimen chosen. The authors are therefore trustful that LCSS might gain a general acceptance by all people involved in lymphatic peripheral disease treatment.

\section{Aknowledgement}

Authors kindly thank Mr. Pietro Gravina N.D. for his invaluable technical support.

\section{References}

1. Rutherford RB, Padberg FT, Camerota AJ, Kistner RL, Meissner MH, et al. (2002) Venous severity scoring: An adjunct to venous outcome assessment. J Vasc Surg 36(5): 889-895.

2. Meissner MH, Natiello C, Nicholls SC (2002) Performance characteristics of the venous clinical severity score. J Vasc Surg 36(5): 889-895.

3. (2013) International Society of Lymphology, The diagnosis and treatment of peripheral lymphedema: 2013 Consensus Document of the International Society of Lymphology. Lymphology 46(1): 1-11.

4. (2002) Organizzazione Mondiale della Sanità: ICF Classificazione Internazionale del Funzionamento, della Disabilità e della Salute. Erickson Gardiolo.

5. Foldi M, Foldi E (2009) Foldi's Textbook of Lymphology, Elsevier, San Francisco, USA.

6. Michelini S (1998) Phlebolymphoedema. From diagnosis to therapy. Edizioni PR Bologna.

7. Gasbarro V, Michelini S, Antignani PL, Tsolaki E, Ricci M, et al. (2009) The CEAP-L classification for lymphedemas of the limbs : the Italian experience. Int Angiol 28(4): 315-324.

\section{ISSN: 2574-1241}

DOI: 10.26717/BJSTR.2018.08.001670

Guido Valle MD. Biomed J Sci \& Tech Res (C) (P) This work is licensed under Creative

Submission Link: https://biomedres.us/submit-manuscript.php
8. Michelini S, Campisi C, Failla A, Boccardo F, Moneta G (2006) Staging of Lymphedema: Comparing different proposal. European Journal of Lymphology 16(46): 7-10.

9. Olszewski W (1996) Recurrent bacterial dermatolymphangioadenitis (DLA) is responsible for progression of lymphoedema. Lymphology 29: 331.

10. Stewart FW, Treves N (1948) Lymphangiosarcoma in postmastectomy lymphedema; a report of six cases in elephantiasis. Cancer 1(1): 64-81.

11. Michelini S, Failla A (1997) Linfedemi: Inquadramento diagnostico clinico e strumentale. Minerva Cardioangiologica 45(6): 11-15.

12. Michelini S (1998) Phlebolymphoedema. From diagnosis to therapy. Edizioni PR Bologna

13. Michelini S, Failla A, Moneta G, Zinicola V, Romaldini (2007) International classification of lymphedema functioning and disability evaluation. Eur J Lymphology 17(51): 16-19.

14. Collin C, Wade DT, Davies S, Horne V (1988) The Barthel ADL Index: a reliability study. Int Disabil Stud 10: 61-63.

15. Michelini S, Failla A, Moneta G, Campisi C, Boccardo F (2002) Clinical staging of lymphedema and therapeutical implications. Lymphology 35 : 168-176.

16. (2012) International Lymph Framework: Best practice for the management of lymphoedema. ( $2^{\text {nd }}$ Edition $)$.

17. Michelini S, Failla A, Moneta G, Cardone M, Michelotti L, et al. (2008) Linee guida e protocolli diagnostico-terapeutici nel linfedema. Eur Med Phys 44(1-3).

18. Lee BB, Bergan J, Rockson SG (2011) Lymphedema. A concise compendium. Theory and Practice, Springer-Verlag - London, UK.

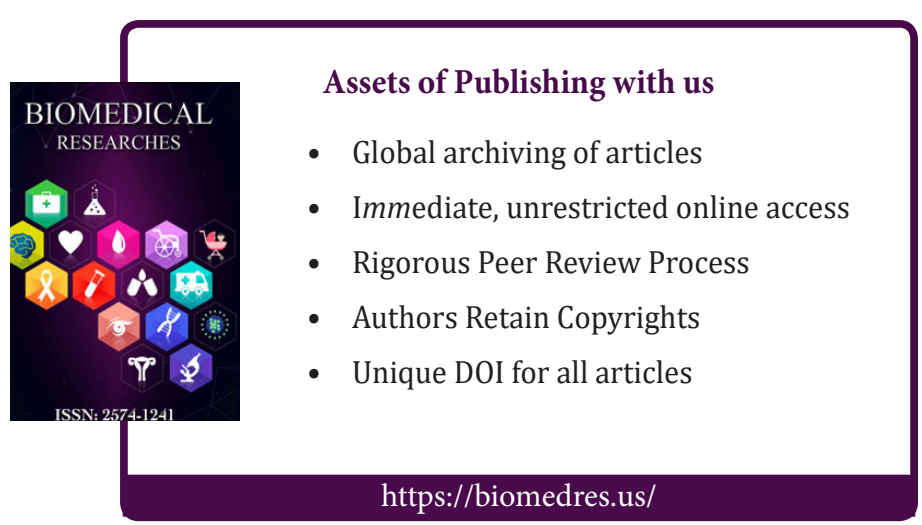

